\title{
Listagem de Medicamentos e a \\ Decisão Proferida na STA N. 59-STJ. \\ A Justiciabilidade dos Direitos Sociais
}

Luiz Fernando Gaspar Costa ${ }^{(*)}$

\section{I - INTRODUÇÃO}

Motiva as considerações adiante pontuadas o proferimento de decisão monocrática do Senhor Ministro Presidente do Superior Tribunal de Justiça nos autos de suspensão de tutela antecipada (STA n. 59; DJ 2.2.2004), em que foi determinada a suspensão dos efeitos de tutela antecipada concedida para o fim de desobrigar a União Federal, o Estado de Santa Catarina e o Município de Chapecó do cumprimento de ordem judicial que determina o fornecimento gratuito e ininterrupto de medicamentos não padronizados pelos órgãos estatais, quando considerados necessários a qualquer espécie de tratamento médico.

A proposta é partir do paradigma já referido para ponderar a respeito de alguns aspectos referentes à justiciabilidade dos direitos sociais, tema cujo debate é de movimento crescente nas atuais doutrina e jurisprudência. Ainda é incipiente a discussão acerca do assunto e muitas dúvidas há a seu respeito, notadamente no que diz com a ausência de parâmetros a serem levados em consideração no exercício do controle jurisdicional de políticas públicas. Sem pretensão de fazê-lo com rigor acadêmico, o propósito é o de, à vista do caso concreto, esboçar algumas reflexões acerca de assunto cuja relevância decorre diretamente da necessidade de efetivação das normas constitucionais contempladoras dos direitos sociais.

\section{II - DECISÃO MONOCRÁTICA PROFERIDA NOS AUTOS DE SUSPENSÃO DE TUTELA ANTECIPADA N. 59/03, EM TRÂMITE PERANTE O SUPERIOR TRIBUNAL DE JUSTICCA - ANTECEDENTES PROCESSUAIS E CONTEÚDO}

Em 27.9.2002 o Ministério Público Federal propôs ação civil pública em face da União Federal, do Estado de Santa Catarina e do Município de

(*) Procurador da República, Ministério Público Federal da 3 Região. E-mail: Ifcosta@ prsp.mpf.gov.br 
Chapecó com o fim de obter a condenação destes, de forma solidária, 'ao fornecimento gratuito e ininterrupto, através da Secretaria de Saúde do Município de Chapecó, a todos doentes que porventura necessitarem, de medicamento independente desse constar na lista oficial do Ministério da Saúde'(1). Por meio dessa ação também foi pleiteada a condenação dos citados entes da federação ao fornecimento do medicamento necessário ao tratamento de um paciente determinado; tal medicamento não constava da Relação Nacional de Medicamentos - RENAME, editada pelo Ministério da Saúde.

Pelo Juízo Federal da Subseção Judiciária de Chapecó foi concedida a antecipação de tutela para 'determinar aos réus, observadas as regras de competência na administração do SUS, a fornecerem à paciente (...) o medicamento recusado na esfera administrativa, na quantidade necessária, $e$ a outras pessoas os medicamentos necessários ao tratamento de saúde, independentemente da listagem oficial da RENAME (...)'(2) (g. n.).

Contra tal decisão a União Federal interpôs agravo de instrumento perante o Tribunal Regional Federal da 4⿳亠丷厂 Região que, ao julgar o mérito do recurso, negou-lhe provimento e manteve a decisão do Juízo de primeiro $\operatorname{grau}^{(3)}$.

Tendo em vista o conteúdo do acórdão a União Federal interpôs, perante o Presidente do Superior Tribunal de Justiça, pedido de suspensão de tutela antecipada ${ }^{(4)}$, com fundamento no art. $4^{\circ}$ da Lei n. 8.437/92 ${ }^{(5)}$.

Da apreciação de tal pedido é que adveio a decisão monocrática ${ }^{(6)}$ referida neste tópico, por meio da qual foi suspensa a eficácia da ordem judicial que determina o fornecimento gratuito e ininterrupto de medicamentos não padronizados pelos órgãos estatais. Nela argumentou-se, em síntese, com a potencialidade de a decisão impugnada causar lesão à ordem e à saúde públicas; afirmou-se que impor o fornecimento de medicamento não con-

(1) Pedido principal formulado na referida Ação Civil Pública subscrita pelo Procurador da República Dr. Cláudio Dutra Fontella, proposta perante a Vara Federal da Subseção Judiciária de Chapecó em 16.10.02.

(2) Decisão interlocutória proferida pelo Juiz Federal Dr. Roberto Fernandes Júnior nos autos da Ação Civil Pública n. 2002.72.02.004552-1, referida na decisão monocrática do Ministro Presidente do Superior Tribunal de Justiça in SUPERIOR TRIBUNAL DE JUSTIÇA. Disponivel em: <http://www.stj.gov.br/webstj/>. Acesso em: 16 maio 2004.

(3) Acórdão da $3^{\text {a }}$ Turma do Tribunal Regional Federal da $4^{\text {a }}$ Região, referido na decisão monocrática do Ministro Presidente do Superior Tribunal de Justiça in http://www.stj.gov.br/ webstj/ (STA 59) em 15.5.04, 17h10min.

(4) Interpôs também recursos especial e extraordinário.

(5) "Art. 4을 Compete ao presidente do tribunal, ao qual couber o conhecimento do respectivo recurso, suspender, em despacho fundamentado, a execução da liminar nas ações movidas contra o Poder Público ou seus agentes, a requerimento do Ministério Público ou da pessoa jurídica de direito público interessada, em caso de manifesto interesse público ou de flagrante ilegitimidade, e para evitar grave lesão à ordem, à saúde, à segurança e à economia públicas" (caput) (g.n.).

(6) A decisão foi proferida pelo Ministro Nilson Naves, então Presidente do Superior Tribunal de Justiça. 
templado na relação nacional de medicamentos (RENAME) em sede de tutela antecipada implicou incursão indevida em seara exclusiva da Administração, tendo em vista que a escolha dos medicamentos a serem adotados na Política Nacional de Medicamentos segue procedimentos baseados em critérios técnico-científicos e tal ingerência culminaria por afetar a saúde pública; ressalvou, ao mencionar decisão anterior, que não se afastava a possibilidade de, em casos isolados, "mediante comprovação da utilidade e necessidade do tratamento com a medicação objeto da controvérsia, o interessado obter do Judiciário respaldo para seu pleito, como vem ocorrendo".

\section{III - SAÚDE COMO DIREITO SOCIAL}

Não há como desenvolver análise conseqüente acerca da efetivação do direito à saúde sem situá-lo no contexto de seu reconhecimento. Nesse sentido, falar em direito à saúde é falar em direito humano social. E ao 'surgimento' da categoria direitos humanos sociais é comum associar-se os movimentos sociais do século XIX. Segundo classificação tradicional(7) no Direito Constitucional, o reconhecimento dos direitos humanos comportaria quatro categorias históricas distintas. O surgimento dos direitos de primeira geração têm correspondência historicamente às revoluções liberais dos séculos XVIII e XVIII. Seu conteúdo diz essencialmente com o reconhecimento da autonomia dos indivíduos em face do Estado e entre si. Também conhecidos como liberdades civis ou liberdades-autonomia ${ }^{(8)}$, tais direitos implicam o reconhecimento da independência do indivíduo e correspondem, no ordenamento jurídico brasileiro, às categorias direitos civis e direitos políticos. Como na maior parte das vezes sua efetivação implica a não interferência do Estado, um não-atuar estatal, tais direitos são também conhecidos por liberdades negativas. Já os direitos de segunda geração "surgiram" por força dos movimentos e doutrinas sociais do século XIX. As características de tal período correspondem em parte às características do próprio conceito modernização, dado pela doutrina social;

(7) Pese a recorrência da doutrina em mencionar tal classificação ela não é totalmente imune a críticas. Nesse sentido, Carlos Weis objeta que (1) o termo geração induz à idéia de sucessão, segundo a qual ataria-se o fim de uma linhagem ao inicio de otra. Ocorre que a história aponta para o surgimento concomitante de textos jurídicos que se referem ora a uma, ora a outra "geração". llustra, no plano internacional, com o surgimento da Organização Internacional do Trabalho em 1919, que proporcionou a regulamentação de diversos direitos sociais antes mesmo de serem internacionalmente reconhecidos os direitos civis e politicos. Além disso, (2) tal classificação, ao dispor os direitos em categorias históricas, reflete concepção que vê o surgimento dos direitos humanos como decorrente de injunções histórico-políticas (concepção historicista). Opõe, ainda, que (3) falar em geração significa, nas ciências naturais, falar em algo que se reproduz por si mesmo; ao trazer tal metáfora para o estudo dos direitos humanos traz-se também a falsa idéia de que os direitos teriam força para "gerar" outros direitos, que viriam a substituir os primeiros. WEIS, Carlos. "Direitos humanos contemporâneos". São Paulo: Malheiros Ed., 1999, pp. 40-42.

(8) SILVA, José Afonso da. "Curso de direito constitucional positivo". São Paulo: Malheiros Ed., 1999, p. 187. 
nesse sentido, pode-se destacar a formação de capital e mobilização de recursos, o desenvolvimento das forças produtivas e o aumento da produtividade do trabalho ${ }^{(9)}$, processos que ganham força extraordinária no contexto da Revolução Industrial. Tais processos trouxeram benefícios, mas também tiveram seu lado perverso, cuja expressão contundente foi a exploração do trabalho, em sentido amplo (carga horária de trabalho extensa, insalubridade do ambiente do trabalho, exploração do trabalho infantil são apenas alguns exemplos). Nesse contexto é que surgiram os movimentos de trabalhadores, que começam a demandar do Estado uma intervenção nas relações de trabalho. As mudanças sociais decorrentes do processo de modernização passam então a demandar um atuar do Estado, um agir estatal, cuja demanda começou com relação ao trabalho, mas no decorrer do tempo ampliou-se para outros direitos sociais. Esse é um momento que corresponde ao chamado Constitucionalismo Social, cujas primeiras expressões podem ser identificadas na Constituição Francesa de 1848, na Constituição Mexicana de 1917, na Declaração dos Direitos do Povo TrabaIhador e Explorado, de 1918 e na Constituição da Alemanha de 1919(10). O Estado agora, mais do que manter-se em posição passiva, de não-intervenção na esfera individual, passa a ter o dever de atuar positivamente, de ir além da concepção liberal para assegurar também os chamados direitos de igualdade. Aqui surgirá a necessidade de definição de políticas públicas para sua efetivação; isso porque, como já se disse, os direitos sociais, mais do que a mera omissão estatal, demandam um atuar público, que implicará o necessário aporte de recursos orçamentários, além da definição de como se dará a prestação de tal serviço público, se diretamente ou por meio de terceiros, com a devida fiscalização pelo Estado(11). Nesse tipo jurídico direitos humanos sociais - podemos situar o direito à saúde. A doutrina jurídica prossegue na classificação definindo direitos de terceira geração como aqueles que dizem à Humanidade como um todo (direito ambiente equilibrado e direito à paz são exemplos), e os de quarta geração, decorrentes do desenvolvimento da globalização política ${ }^{(12)}$ (pluralismo e democracia são exemplos). Os direitos de terceira e quarta gerações são também conhecidos como direitos de fraternidade.

Como desdobramento desses processos históricos referidos podem ser mencionados, no plano internacional, os documentos e tratados internacionais relativos aos diversos "tipos" de direitos. A subscrição de tais pactos por diversos países, dentre eles o Brasil, implica um compromisso internacional com a efetivação dos direitos, e não apenas seu reconhecimento formal. No

(9) HABERMAS, Jürgen. "O discurso filosófico da modernidade". São Paulo: Martins Fontes, 2002 , p. 5.

(10) WEIS, Carlos, op. cit., p. 39.

(11) FRISCHEISEN, Luiza Cristina Fonseca. "Políticas públicas". Aula proferida durante o I Curso de Especialização em Direito Público, 15 de agosto de 2001 - São Paulo. Escola Superior do Ministério Público do Estado de São Paulo, 2001.

(12) BONAVIDES, Paulo. "Curso de direito constitucional". São Paulo: Malheiros Ed., 1999, p. 525. 
que diz especificamente com o direito à saúde, pode-se ressaltar, como documento, a Declaração Universal dos Direitos Humanos de $1948^{(13)}$, que em seu artigo XXV, item 1, dispõe que "toda pessoa tem direito a um padrão de vida capaz de assegurar a si e a sua familia saúde e bem-estar, inclusive alimentação, vestuário, habitação, cuidados médicos, e os serviços sociais indispensáveis, o direito à segurança, em caso de desemprego, doença, invalidez, viuvez, velhice ou outros casos de perda dos meios de subsistência em circunstâncias fora de seu controle" e como tratado, o Pacto Internacional dos Direitos Econômicos, Sociais e Culturais, assinado em 16 de dezembro de 1966 e ratificado pelo Brasil em 24 de janeiro de 1992, dispõe, em seu artigo 12 que: "1.Os Estados-partes no presente Pacto reconhecem o direito de toda pessoa de desfrutar o mais elevado nível de saúde física e mental. 2. As medidas que os Estados-partes no presente Pacto deverão adotar, com o fim de assegurar o pleno exercício desse direito, incluirão as medidas que se façam necessárias para assegurar: (...) A prevenção e o tratamento das doenças epidêmicas, endêmicas, profissionais e outras, bem como a luta contra essas doenças"(14) (g. n.). Sem ingressar na discussão doutrinária a respeito da natureza jurídica do status adquirido pelos Tratados Internacionais quando ratificados pela República Federativa do Brasil, o fato é que implicam obrigatoriedade de cumprimento uma vez incorporados ao ordenamento jurídico brasileiro.

A disciplina internacional incorporada mostra-se plenamente conforme aos preceitos consagrados na Constituição Federal de 1988. Para assegurar a saúde - que, conforme a Organização Mundial da Saúde, é "um estado de completo bem-estar físico, mental e social e não apenas a ausência de doença" ${ }^{(15)}$ - como direito social a Carta Magna, em seu art. 6으, dispõe que "São direitos sociais a educação, a saúde, o trabalho, a moradia, o lazer, a segurança, a previdência social, a proteção à maternidade e à infância, a assistência aos desamparados, na forma desta Constituição" e no art. 196 que "A saúde é direito de todos e dever do Estado, garantido mediante políticas sociais e econômicas que visem à redução do risco de doença e de outros agravos e ao acesso universal e igualitário às ações e serviços para sua promoção, proteção e recuperação".

A Constituição Federal também impõe a todos os entes da Federação a responsabilidade política pela tutela da saúde, ao dispor sobre a competência administrativa comum à União, aos Estados, ao Distrito Federal e aos Municípios, impondo a eles o dever de cuidar da saúde e assistência pública, da proteção e garantia das pessoas portadoras de deficiência (art. 23, II,

(13) A Declaração, apesar de não ser tipologicamente classificada como tratado internacional, foi assinada pelo Brasil na condição de membro da Assembléia Geral das Nações Unidas em 10.dez.48.

(14) A menção feita à Declaração Universal dos Direitos Humanos e do Pacto Internacional dos Direitos Econômicos Sociais e Culturais é apenas indicativa; neles não se esgota a disciplina internacional sobre o direito à saúde.

(15) Who Health Organization. Disponivel em: <http://www.who.int/en/>. Acesso em: 16 maio 2004. 
da Constituição Federal), ao disciplinar a competência legislativa comum à União, aos Estados e ao Distrito Federal para legislar sobre previdência social, proteção e defesa da saúde (art. 24, XII, da Constituição Federal) e ao dispor sobre competência dos Municípios em prestar, com a cooperação técnica e financeira da União e do Estado, serviços de atendimento à saúde da população (art. 30, VII, da Constituição Federal).

Da Constituição Federal depreende-se ainda que a execução das ações e dos serviços de saúde (política pública de saúde) será feita tanto diretamente pelo Poder Público, quanto por meio de terceiros. Dispõe o art. 197 que "São de relevância pública as ações e serviços de saúde, cabendo ao Poder Público dispor, nos termos da lei, sobre sua regulamentação, fiscalização e controle, devendo sua execução ser feita diretamente ou através de terceiros e, também, por pessoa física ou jurídica de direito privado". Para que a execução de tal política nacional seja conseqüente imprescindível se faz a organização de um sistema administrativo planificador, notadamente tendo em vista que o Estado Brasileiro adotou o modelo federativo. $E$ assim o fez a Constituição Federal em seu art. 197, que estabelece as linhas mestras desse sistema ao dispor que "As ações e serviços públicos de saúde integram uma rede regionalizada e hierarquizada e constituem um sistema único, organizado de acordo com as seguintes diretrizes: I - descentralização, com direção única em cada esfera de governo; II - atendimento integral, com prioridade para as atividades preventivas, sem prejuizo dos serviços assistenciais; III - participação da comunidade" (g. n.). Portanto, em que pese a dualidade subjetiva na execução da política de saúde, as ações devem estar conformes a diretrizes estabelecidas pelo Sistema Único de Saúde, como expressão da planificação buscada pela Constituição Federal.

\section{IV - CONTROLE JUDICIAL DE POLÍTICAS PÚBLICAS. ALGUNS MARCOS CONSTITUCIONAIS}

Já recordamos que os direitos de segunda geração - dentre os quais situa-se o direito à saúde - "surgiram" por força dos movimentos e doutrinas sociais do século XIX e que o Estado, mais do que se manter em posição passiva, passa a ter o dever de atuar positivamente, para assegurar também os chamados direitos de igualdade. A existência formal de política pública regulamentada não autoriza concluir, por si só, que ela esteja em perfeito funcionamento e de acordo com os vetores que a Constituição Federal e os tratados internacionais estabelecem para a satisfação dos interesses por ela tutelados. Como bem explica Luiza Cristina Fonseca Frischeisen, "quando se pensa em política pública social, em direito social, estão presentes quatro questões: declaração do direito social; a ordem social constitucional (como se delineia aquela política pública social); onde está a previsão orçamentária (se há um fundo para implementação); quem controla, quem tem a gestão dessa política pública (conselhos gestores, que são o controle civil dos orçamentos 
públicos)"(16) e uma vez que seja constatada a omissão do Estado na implementação das políticas públicas, haverá dois caminhos possíveis: "um de reivindicação política, onde quanto mais for real a democracia, mais amplos serão os debates, que não são necessariamente político-partidários, mas sim por grupos e associações" e outro "pela justiciabilidade do direito social que é possível porque começa a haver demandas no Judiciário - individuais ou coletivos - para a implementação de direitos sociais (como, por exemplo, a demanda proposta pela pessoa que não tem dinheiro para comprar um determinado remédio e o SUS tem a obrigação de fornecer e impetrar Mandado de Segurança para obter o fornecimento da medicação)"(17).

Para aquelas situações em que o acesso à Justiça é pleiteado em razão da omissão na formulação de políticas públicas ou seu mau funcionamento, surgirão questões jurídicas de discussão altamente complexa. $\mathrm{Na}$ lúcida observação de José Reinaldo de Lima Lopes, referindo-se aos direitos sociais: "São estes direitos que dependem, para sua eficácia, de uma ação concreta do Estado, e não simplesmente de uma possibilidade de agir em juízo. Existe, fundamentalmente, uma dupla série de questões jurídicas a serem enfrentadas. Em primeiro lugar, (1) trata-se de saber se os cidadãos em geral têm ou não o direito de exigir, judicialmente, a execução concreta de políticas públicas e a prestação de serviços públicos. Em segundo lugar, (2) trata-se de saber se e como o Judiciário pode provocar a execução de tais políticas" (18).

Para tratar de tema da envergadura da justiciabilidade de direitos sociais é imprescindivel pontuar, além da disciplina constitucional relativa à saúde referida no item III, que: 1) a elaboração de políticas públicas está adstrita à rígida observância dos princípios constitucionais, dentre os quais, nunca é demais lembrar, assumem fundamental importância o princípio da dignidade da pessoa humana (art. 1으, inciso III, da Constituição Federal) e os objetivos fundamentais da República Federativa do Brasil (dos quais destacam-se o de construir uma sociedade livre, justa e solidária o de erradicar a pobreza e a marginalização e reduzir as desigualdades sociais e regionais); 2) o princípio da soberania popular, que tem como um de seus desdobramentos o exercício da democracia representativa (art. $1^{\circ}$, parágrafo único, da Constituição Federal), harmonizado com o princípio da legalidade (arts. 5, II e 37, caput, da Constituição Federal) faz concluir que o Poder Legislativo é, por excelência, o legitimado a definir, sempre em conformidade com os ditames da Constituição, qual o rumo que tais políticas públicas deverão tomar, inovando a ordem jurídica; 3) o Poder Executivo deverá dar efeito a tais políticas em fiel

(16) FRISCHEISEN, Luiza Cristina Fonseca, op. cit.

(17) Id. Ibid.

(18) LOPES, José Reinaldo de Lima. "Crise da norma juridica e a reforma do Judiciário". In: FARIA, José Eduardo (Org.). "Direitos humanos, direitos sociais e justiça". São Paulo: Malheiros Ed., 1998, p. 130. 
observância aos ditames da lei (art. 84, IV, da Constituição Federal); 4) ao Poder Judiciário está reservado, quando provocado, o controle jurisdicional das políticas públicas em face das leis e da Constituição, como decorrência inequívoca do princípio da inafastabilidade da jurisdição (art. 5ㄴ, XXXV, da Constituição Federal); 5) à pessoa está resguardado o direito de socorrer-se ao Judiciário, como decorrência do princípio anterior, quer por meio de tutela individual quer pela coletiva, na forma da lei; 6) por serem impostos ao Ministério Público os misteres de promover a defesa da ordem jurídica, do regime democrático e dos interesses sociais e indisponiveis (art. 127, caput, da Constituição Federal), de zelar pelo efetivo respeito dos poderes públicos e dos serviços de relevância pública aos direitos assegurados na Constituição (art. 129, II, da Constituição Federal) e de promover a proteção do patrimônio público e social, do meio ambiente e outros interesses difusos e coletivos (art. 129, III, da Constituição Federal) a ele se impõe o dever de manejar os instrumentos que a Constituição Federal e a legislação Ihe faculta, dentre os quais merecem destaque o inquérito civil e a ação civil pública ${ }^{(19)}$; 7) não se pode simplesmente ignorar que existe uma ordem financeira constitucionalmente estruturada, que impõe ao Estado a observância do plano plurianual, das diretrizes orçamentárias e dos orçamentos anuais (art. 165, caput, da Constituição Federal); que a seguridade tem orçamento próprio (art. 165, § 5, III, da Constituição Federal) e que é vedada a realização de despesas ou a assunção de obrigações diretas que excedam os créditos orçamentários ou adicionais (art. 167, III, da Constituição Federal).

Postos tais parâmetros, podemos refletir sobre se é possível e como compatibilizá-los de maneira a se preservar, a um só tempo, a efetividade do direito à saúde e a necessária observância das limitações orçamentárias, tendo como pano de fundo a questão posta do fornecimento gratuito e ininterrupto de medicamentos não padronizados pelos órgãos estatais.

Sem pretensão nenhuma de solucionar questão de tal, o propósito aqui é apenas de estimular o debate e evitar a saída cômoda da negativa pelo uso da construção dogmática da reserva do possível. J. J. Gomes Canotilho coloca bem a questão: "Os direitos de liberdade não custam, em

(19) Os mecanismos mencionados certamente não exaurem as vias de que o Ministério Público pode se valer no exercicio de suas funções institucionais. Poderiamos a eles acrescentar outros instrumentos de natureza jurisdicional: promoção da ação direta de inconstitucionalidade e respectivo pedido de medida cautelar (CF, 103, VI; CF, 109, IV; LC n. 75/93, artigo 6o, I); promoção da ação direta de inconstitucionalidade por omissão (CF, 103, VI e § 2º; CF, 109, IV; LC n. $75 / 93$, artigo 6으. II); promoção da ação declaratória de constitucionalidade $\left(C F, 103\right.$, VI e $\S 4^{\circ}$ ); promoção da argüição de descumprimento de preceito fundamental (CF, 102, § 1ㅇ; LC n. 75/93, artigo 6일 III); representação para intervenção nos Estados e no Distrito Federal (CF, 34, VII, e; 35, III; 36, III; 109, IV; LC n. 75/93, artigo 6ㅇ, IV); impetração de mandado de segurança (LC

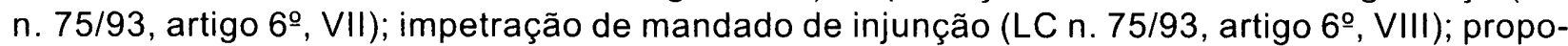
situra de toda e qualquer ação necessária à defesa da saúde, porque de interesse próprio da ordem social (LC n. 75/93, artigo 6․, XIV, c) e de natureza não jurisdicional, como representação ao Congresso Nacional (LC n. 75/93, artigo 6으, XVIII, b); ao Tribunal de Contas (LC n. 75/93, artigo $6^{\circ}, \mathrm{XVIII}, c$ ) e a expedição de recomendações (LC n. 75/93, artigo 6으. XVIII, c). 
geral, muito dinheiro, podendo, ser garantidos a todos os cidadãos sem se sobrecarregarem os cofres públicos. Os direitos sociais, pelo contrário, pressupõem grandes disponibilidades financeiras por parte do Estado. Por isso, rapidamente se aderiu à construção dogmática da reserva do possivel Norbehalt des Möglichen) para traduzir a idéia de que os direitos sociais só existem quando e enquanto existir dinheiro nos cofres públicos. Um direito social sob 'reserva dos cofres cheios" equivale, na prática, a nenhuma vinculação jurídica. Para atenuar essa desoladora conclusão adianta-se, por vezes, que a única vinculação razoável e possível do estado em sede de direitos sociais se reconduz à garantia do mínimo social. Segundo alguns autores, porém, esta garantia do mínimo social resulta já do dever indeclinável dos poderes públicos de garantir a dignidade da pessoa humana e não de qualquer densificação jurídico-constitucional de direitos sociais. Assim, por exemplo, o 'rendimento mínimo garantido' não será a concretização de qualquer direito social em concreto (direito ao trabalho, direito à saúde, direito à habitação) mas apenas o cumprimento do dever de sociabilidade imposto pelo respeito da dignidade da pessoa humana e pelo direito ao livre desenvolvimento da personalidade. Perante a agudeza dessa crítica, desloca-se o cerne da questão para a indeterminabilidade jurídico-constitucional dos direitos fundamentais sociais. "A actuação legislativa nos direitos sociais não está balizada por uma reserva constitucional de conteúdo" (M. Afonso Vaz). Estes nunca legitimarão pretensões jurídicas originárias, isto é, pretensões derivadas directamente dos preceitos constitucionais. Por outras palavras: nenhuma das normas constitucionais garantidoras de direitos sociais fundamentais poderia ser estruturalmente entendida como norma vinculante, garantidora, em termos definitivos, de direitos subjectivos. Os direitos sociais dotados de conteúdo concreto serão os consagrados em normas das regulações legais. Não haverá um direito fundamental à saúde, mas um conjunto de direitos fundados nas leis reguladoras dos serviços de saúde. Não existirá um direito fundamental à segurança social, mas apenas um conjunto de direitos legais sociais (cf., no plano jurisprudencial, Acs. TC 131/92, 508/99, 29/2000)"(20).

\section{V- POLÍTICA NACIONAL DE MEDICAMENTOS E O CONTROLE JUDICIAL NO CASO CONCRETO}

I. Um dos desdobramentos da disciplina normativa do acesso à saúde acima referida é a necessidade da formulação de uma política nacional de medicamentos. Por exigir do Estado atuação positiva - demanda característica dos direitos sociais acima referida - a efetivação do acesso à saúde necessita da planificação racional do atuar estatal. No que diz respeito aos medicamentos esse atuar, como conseqüência lógica, também deve ser disci-

(20) CANOTILHO, J. J. Gomes. "Direito constitucional e teoria da constituição", 4ª ed. Coimbra: Almedina, 2000, p. 471. 
plinado por meio de uma política pública nacional. Para que se possa discutir com alguma seriedade a decisão judicial referida na introdução é imprescindível identificar se existe normatização a respeito do assunto.

A própria Constituição Federal, em seu artigo 200, estabelece como uma das atribuições do Sistema Único de Saúde - SUS - o controle e a participação na produção de medicamentos: "Ao sistema único de saúde compete, além de outras atribuições, nos termos da lei: I - controlar e fiscalizar procedimentos, produtos e substâncias de interesse para a saúde e participar da produção de medicamentos, equipamentos, imunobiológicos, hemoderivados e outros insumos". Tal atribuição veio explicitada pela Lei Orgânica da Saúde (Lei n. 8.080, de 19 de setembro de 1990), que em seu art. 6- inciso VI, enuncia como uma das atribuições do SUS a formulação da política de medicamentos, equipamentos, imunobiológicos e outros insumos de interesse para a saúde e a participação na sua produção.

É no contexto da execução da política nacional de medicamentos, prevista na Constituição e na legislação vigente, que surge a elaboração, pelo Poder Público de uma relação nacional de medicamentos. Como justificativa para tal consolidação apontam-se, de maneira geral, a desorganização na aquisição de medicamentos pelo Estado e a ausência de critérios epidemiológicos ou terapêuticos na aquisição não planificada; como resultados, a padronização proporcionaria a redução do custo na aquisição dos medicamentos e a escolha de medicamentos mais adequados à população no que diz respeito ao risco/benefício, entre outras vantagens ${ }^{(21)}$.

(21) Na justificativa prestada por ocasião da elaboração do Projeto de Lei $n$. 324, de 1999, do Senado Federal, de autoria do Senador Lúcio Alcântara, encontra-se interessante escorço histórico sobre o surgimento e disciplina normativa das relações de medicamento: "(...) A necessidade da elaboração de relações de medicamentos essenciais foi, em verdade, uma evolução dialética, coincidente com um patamar mais elevado de conscientização dos povos, mormente aqueles do chamado Terceiro Mundo, na busca da excelência das ações de saúde pública. $A$ desorganização e falta de profissionalismo, aliados a uma galopante corrupção resultava, nesses paises, no comprometimento, com medicamentos, de percentuais superiores a $60 \%$ do orçamento total do setor saúde, quando o máximo aceitável não deveria ultrapassar os $10 \%$. Tal fato ocorria, via de regra, devido à aquisição quase anárquica de medicamentos, com base em nenhum formulário ou, pior, em múltiplos formulários, sem qualquer critério epidemiológico, ou mesmo terapêutico, com vistas à saúde pública local, regional ou nacional.

Aparentemente, Cuba foi o primeiro país a adotar tal medida, premida pelas retaliações dos países capitalistas no periodo pós-revolução. Efetivou a fusão, em 1961, das 14 plantas industriais farmacêuticas existentes no pais num aglomerado que se denominou "Empresa Consolidada de Produtos Farmacêuticos". Essa empresa passou a funcionar tendo por base um elenco finito de medicamentos essenciais, composto por 611 apresentações, que passaria, em 1975, a ser constituído por 855 formas farmacêuticas.

O Brasil, apesar de não estar sob um tal regime de pressões insuportáveis, adotou, de forma pioneira, o conceito da relação dos medicamentos essenciais como base de uma política nacional de assistência farmacêutica por meio do Decreto n. 53.612, de 26.2.64. Tal relação pioneira teve a denominação de "Relação Básica e Prioritária de Produtos Biológicos e Materiais para Uso Humano e Veterinário". Inobstante as boas intenções, essa relação não foi viabilizada, à época. A concretização só aconteceria, mesmo, com a implantação da Central de Medicamentos (Decreto n. 68.806 de 26.6.71) e com a publicação da primeira "relação de medicamentos 
Da legislação que disciplina o assunto, além da Lei Orgânica da Saúde, já referida, podemos ressaltar: 1) a Lei Federal n. 10.742, de 6 de outubro de 2003, que em seu artigo 3ํํㄹ define medicamento como todo produto farmacêutico, tecnicamente obtido ou elaborado, com finalidade profilática, curativa, paliativa ou para fins de diagnóstico, no que seguiu o mesmo teor do que dispunha o art. $4^{\circ}$, inciso II, da Lei n. 5.991, de 17 de dezembro de 1973; 2) a Lei n. 9.787, de 10 de fevereiro de 1999, que estabelece, em seu art. 3, que as aquisições de medicamentos, sob qualquer modalidade de compra, e as prescrições médicas e odontológicas de medicamentos, no âmbito do Sistema Único de Saúde - SUS, adotarão obrigatoriamente a Denominação Comum Brasileira (DCB) ou, na sua falta, a Denominação Comum Internacional ( $\mathrm{DCl}$ ), além de impor à Agência Nacional de Vigilância Sanitária a obrigação de, periodicamente, publicar a relação de medicamentos registrados no País, de acordo com a classificação farmacológica da Relação Nacional de Medicamentos Essenciais - RENAME; 3) a Lei $n$. 6.360 , de 23 de setembro de 1976, que dispõe sobre a vigilância a que estão sujeitos os medicamentos, drogas, insumos farmacêuticos e outros produtos; e 4) a Resolução da Diretoria Colegiada da Agência Nacional de Vigilância Sanitária - RDC n. 26, de 17 de dezembro de 1999, que, com fundamento no art. 24 da Lei n. 6.360, de 23 de setembro de 1976 (que dispõe sobre a isenção de registro dos medicamentos novos, destinados exclusivamente a uso experimental) instituiu o Programa de Acesso Expandido a medicamentos não registrados no País ou com estudos em desenvolvimento no Brasil ou no país de origem.

Da normatização acima referida convém destacar a disciplina dada pela Lei n. 6.360, de 23 de setembro de 1976. De sua leitura depreende-se a existência de alguns pontos que, em caráter vinculado, determinam o sentido da atividade de vigilância sanitária no que diz respeito aos medicamentos objeto de registro. A relação de medicamentos registrados deve seguir a classificação da Relação Nacional de Medicamentos Essenciais (tais listas não se confundem, são distintas), conforme dispõe a Lei n. 9.787/99. No que diz respeito ao registro de medicamentos destacam-se: 1) a normatização da nomenclatura dos produtos, que não poderão ter nomes ou designações que induzam a erro; veda-se também a atribuição de nome igual ou assemelhado para produtos de diferente composição além de impor regras para a identificação de medicamentos que contêm uma única substância ativa sobeja-

essenciais" (Decreto n. 69.451, de 10.11.71), com cerca de 88 formas farmacêuticas. Ficou patente, de imediato, que a base de funcionamento de um órgão que se pretendia gestor de uma politica nacional de assistência farmacêutica apoiava-se sobre a existência de um formulário de medicamentos essenciais.

Dentre as razões mais relevantes da importância dos formulários de medicamentos essenciais foram listadas as seguintes: as compras centralizadas mais baratas; o controle de preço pela montagem de matrizes de custos; a redução dos preços pela simplificação das embalagens; a compatibilização nosologia x terapêutica; a liberação do receituário de marcas de fantasia; a escolha de medicamentos clássicos, com melhor relação risco/benefício; a escolha de medicamentos resistentes às condições climáticas do Pais. (...)" 
mente conhecida; 2) a normatização do controle de eficácia dos medicamentos, quer no art. 6․, em que dispõe que "a comprovação de que determinado produto, até então considerado útil, é nocivo à saúde ou não preenche requisitos estabelecidos em lei implica na sua imediata retirada do comércio e na exigência da modificação da fórmula de sua composição e nos dizeres dos rótulos, das bulas e embalagens, sob pena de cancelamento do registro e da apreensão do produto, em todo o território nacional", quer no art. $7^{\circ}$, quando autoriza, como medida de segurança sanitária e à vista de razões fundamentadas do órgão competente, a suspensão da fabricação e venda de qualquer dos produtos de que trata a Lei, ainda que registrados, quando se torne suspeito de ter efeitos nocivos à saúde humana; 3) A regulamentação dos requisitos (art. 16) a serem atendidos para que o registro de drogas, medicamentos, insumos farmacêuticos e correlatos seja feito, dentre eles: o de que o produto, através de comprovação científica e de análise, seja reconhecido como seguro e eficaz para o uso a que se propõe, e possua a identidade, atividade, qualidade, pureza e inocuidade necessárias; tratando-se de produto novo, devem ser oferecidas amplas informações sobre a sua composição e o seu uso, para avaliação de sua natureza e determinação do grau de segurança e eficácia necessários; a apresentação de amostra para análises e experiências que sejam julgadas necessárias pelos órgãos competentes do Ministério da Saúde; a entrega de amostra acompanhada dos dados químicos e físico-químicos que identifiquem substância nova na composição do medicamento; quando se trate de droga ou medicamento cuja elaboração necessite de aparelhagem técnica e específica, é necessária prova de que o estabelecimento se acha devidamente equipado e mantém pessoal habilitado ao seu manuseio ou contrato com terceiros para essa finalidade; a apresentação de informações econômicas (preço do produto praticado pela empresa em outros países; valor de aquisição da substância ativa do produto, entre outras informações); 4) a obrigatoriedade de cancelamento do registro de drogas, medicamentos e insumos farmacêuticos, sempre que efetuada modificação não autorizada em sua fórmula, dosagem, condições de fabricação, indicação de aplicações e especificações anunciadas em bulas, rótulos ou publicidade; 5) restrições ao registro de medicamento cuja preparação necessite cuidados especiais de purificação, dosagem, esterilização ou conservação, além da 6) vedação de registro de medicamento que não tenha em sua composição substância reconhecidamente benéfica do ponto de vista clínico ou terapêutico.

A necessidade de racional planejamento de uma política nacional de medicamentos fez com que o legislador, dentre outras coisas, fizesse uma opção pela definição prévia de listas. Essa opção implica, de um lado, a definição a priori de quais medicamentos são considerados essenciais à população (RENAME) ${ }^{(22)} \mathrm{e}$, de outro, o estabelecimento de mecanismos de controle de registro.

(22) O estabelecimento de prioridades é questão de inevitável análise no contexto da modernidade. A observação é válida no que diz respeito às escolhas feitas pelo indivíduo e também 
À indagação posta no primeiro parágrafo deste item IV, acerca da existência de uma formalizada política nacional de medicamentos, a resposta deve ser afirmativa. Autoriza-a a constatação de que o legislador ordinário atendeu ao preceito inserto na Constituição Federal e disciplinou uma política pública de medicamentos que, no que diz respeito ao seu registro, é balizada pela normatização da nomenclatura, controle de eficácia e atendimento a requisitos técnico-científicos.

Há ainda de se perquirir se a política nacional de medicamentos dá solução para aquelas situações em que - como no caso concreto levado à apreciação do Ministro Presidente do Superior Tribunal de Justiça - a saúde do paciente está em risco e o medicamento indicado para o seu tratamento não está contemplado na Relação Nacional de Medicamentos Essenciais.

Com relação a medicamentos novos, a Diretoria Colegiada da Agência Nacional de Vigilância Sanitária editou a Resolução RDC n. 26, de 17 de dezembro de 1999 - com o que regulamentou o art. 24 da Lei Federal n. 6.360/76 (com redação dada pela Lei n. 10.742, de 6 de outubro de 2003), que dispõe estarem isentos de registro os medicamentos novos, destinados exclusivamente a uso experimental, sob controle médico, podendo, inclusive, ser importados mediante expressa autorização do Ministério da Saúde. A referida resolução, considerando a necessidade de regulamentar o acesso dos pacientes com doenças graves e que ameaçam à vida, a produtos potencialmente eficazes, não registrados no País ou com estudos em desenvolvimento no Brasil ou no país de origem, na ausência de outras alternativas terapêuticas satisfatórias, instituiu o Programa de Acesso Expandido. Por acesso expandido entende-se o "processo patrocinado de disponibilização de produto novo, promissor, ainda sem registro na Agência Nacional de Vigilância Sanitária - ANVS/MS, que esteja em estudo de fase III em desenvolvimento no Brasil ou no país de

naquelas feitas pelo Estado. O problema que se nos põe a desafiar é como minimizar o espectro perverso que a eleição de prioridades traz. Nesse sentido mostram-se oportunas as observações de Enzensberger: "Com o tempo, ninguém, seja uma coletividade ou um individuo, poderá escapar de avaliar o grau de sua própria responsabilidade e de determinar prioridades. (...)" (g. n.). Adiante, afirma que a determinação de prioridades implica limitação de responsabilidade, que pode levar a bons resultados, que decorrem, dentre outros fatores, da concentração da energia material da atividade humana, mas que também tem um lado obscuro: "Mas o estabelecimento de prioridades possui também um lado obscuro, e seria desonesto não mencioná-lo. A palavra triage vem do francês e significa "escolher", "separar". Esse conceito aparece na medicina de guerra do século XIX. Após as grandes batalhas, os médicos estavam diante da questão de como deveria se dar o tratamento dos feridos em condições dificeis e perigosas de transporte, capacidade limitada de alojamentos médicos e recursos insuficientes de tratamento. Impôs-se de forma mais ou menos explícita a regra da triagem, calcada em uma escolha a partir de três categorias. Feridos leves eram tratados apenas superficialmente e precisavam contar com suas próprias forças para a recuperação. Feridos irrecuperáveis eram deixados à sua própria sorte. Tratamento médico eficaz era garantido apenas àqueles cuja necessidade era aguda ou que tinham boa perspectiva de cura. O dilema dos médicos e voluntários é evidente. Eles tinham que viver com o risco moral contido em qualquer decisão entre vida e morte. Situações semelhantes são comuns na medicina intensiva e de transplante (...") (g.n.). ENZENSBERGER, Hans Magnus. Visões da guerra civil. In: Guerra civil. São Paulo: Companhia das Letras, 1995, pp. 7-67. 
origem e com programa de acesso expandido aprovado no país de origem, ou com registro do produto no país de origem, para pacientes com doenças graves e que ameaçam à vida, na ausência de alternativas terapêuticas satisfatórias disponibilizadas no País, sem ônus adicional para o paciente". Tal regulamento impõe regras relacionadas: 1) à responsabilidade do patrocinador, relativas ao esclarecimento das normas a serem seguidas pelos médicos no uso do produto; à elaboração de termo de informação e adesão do paciente; à prestação de informações sobre o produto; ao registro dos médicos que receberam o produto; ao monitoramento e registros dos produtos entregues a médicos solicitantes e dos estoques físicos restantes; à comunicação à Vigilância Sanitária da ocorrência de eventos adversos graves e inesperados; ao fornecimento de tratamento aos pacientes com doenças crônicas durante o tempo definido, entre outras; 2) à responsabilidade da Agência Nacional de Vigilância Sanitária, dentre as quais está a de analisar os relatos de eventos adversos; e 3) à responsabilidade do médico.

II. No precedente judicial referido afirma-se que imposição do fornecimento de medicamento não contemplado na relação nacional de medicamentos (RENAME) em sede de tutela antecipada implicou incursão indevida em seara exclusiva da Administração, tendo em vista que a escolha dos medicamentos a serem adotados na Política Nacional de Medicamentos segue procedimentos baseados em critérios técnico-científicos. $O$ argumento mostra-se razoável na medida em que em sede cognição superficial o Juiz não teve o amparo de prova pericial que pudesse subsidiar provimento jurisdicional nesse sentido. Contudo, é igualmente razoável supor que se o magistrado for instado a se manifestar a respeito de situação em que o jurisdicionado esteja exposto a risco iminente de saúde, poderá amparar-se do princípio da razoabilidade $^{(23)}$ (ou ponderação de valores) para, sem transgredir aquela esfera de atuação própria do administrador, fazer prevalecer o direito à saúde.

No que diz respeito ao potencial risco à saúde pública, invocado como fundamento bastante a suspender a execução da ordem de fornecimento de medicamentos, o argumento já não se mostra razoável. Isso porque a ordem judicial não pode ser tomada no sentido amplo que se pretendeu dela extrair. Com efeito, ela não poderia implicar a completa desconsideração de toda uma política de medicamentos legalmente implementada e viabilizar a todo paciente o fornecimento de qualquer medicamento que julgasse conveniente usar em seu tratamento. $O$ estrito sentido em que deve ser tomada é bem ilustrado no acórdão por “(...) A concessão de remédios refere-se, especificamente, aos casos em que os receituários indicam medicações necessárias - e insubstituíveis -, porém não constantes da lista da RENAME. Por certo, decisão em sentido favorável ao

(23) Nesse sentido vale mencionar decisão interlocutória proferida pelo Juiz Federal Paulo Alberto Sarno nos autos da Ação Civil Pública n. 2001.61.00.021369-4, em trâmite perante a $18^{a}$ Vara Federal da Subseção Judiciária de São Paulo, em que, tendo ponderado a respeito da pleiteada liberação irrestrita de medicamento não padronizado, determinou à União Federal e à Anvisa que atendessem à demanda dos pacientes por meio do Programa de Acesso Expandido, na forma de seu regulamento. 
pedido formulado pelo Ministério Público Federal, não abriria precedente para a solicitação constante de medicamentos não fornecidos pelo SUS, restringindo-se, apenas, aos casos em que a necessidade do paciente enfermo ultrapassa os limites da listagem da Relação Nacional de Medicamentos (...)"(24) (g. n.)

Interessante também destacar, na decisão, a ressalva feita à possi

3bilidade de, em casos isolados, "mediante comprovação da utilidade e neces-sidade do tratamento com a medicação objeto da controvérsia, o interessado obter do Judiciário respaldo para seu pleito, como vem ocorrendo". Considerando-se que, como visto acima, existe uma política nacional de medicamentos norteada, entre outros critérios, pelo controle de eficácia e aten-dimento a requisitos técnico-científicos e considerando-se que a execução de tal política é imperativo decorrente do próprio princípio da legalidade é de se supor, a priori, que o Poder Público esteja dando efeito ao direito à saúde de maneira satisfatória por meio do instrumental jurídico de que dispõe. Tal presunção, contudo, é relativa, e a própria decisão em comento reconhece-o, ao fazer a ressalva supramencionada. O que demandaria algum esclarecimento é a menção à salvaguarda do direito em "casos isolados"(25).

III. Além dos aspectos expressamente ventilados na decisão poderíamos referir àquelas objeções de natureza orçamentária comumente argüidas para justificar a impossibilidade do cumprimento de ordens judiciais que determinam a implementação de direitos sociais. A questão não é simples: a própria crise do Estado Social(26)(27), a insatisfatória gestão da política nacional de saúde e os efeitos deletérios da corrupção são apenas alguns dos fatores que contribuem para a complexidade no estudo do tema.

(24) A decisão é referida no acórdão por meio do qual o Tribunal Regional Federal da 4⿳亠丷厂 Região manteve a sentença de procedência da Ação Civil Pública n. 2002.72.02.004552-1, publicado no DJU em 12 de maio de 2004.

(25) A se compreender a salvaguarda de "casos isolados" como cláusula que imponha ao julgador a possibilidade de apenas em ações individuais reconhecer o direito de acesso a medicamento, estariamos a compactuar com entendimento juridicamente insubsistente, porque completamente avesso ao comezinho principio da isonomia, além de fugir do mérito da discussão do controle judicial de políticas públicas.

(26) Como explica Campilongo “(...) partidos e sindicatos expandem as técnicas de redistribuição de rendas, direitos e políticas igualitaristas. A crise do Estado Social diminui todas essas virtualidades. Redistribuição, novas formas de agregação e participação, numa fase de escassez de recurso e retração da atividade econômica, podem estar encobrindo fórmulas perversas e parciais de divisão dos recursos públicos e privados. O Judiciário tem, aqui, outro campo farto para atuação e orientação dos "novos atores sociais", especialmente resgatando a norma jurídica como critério objetivo de prática redistributiva e justiça social". CAMPILONGO, Celso Fernandes. Os desafios do Judiciário, um enquadramento teórico. In: FARIA, José Eduardo (Org.), op. cit., p. 130.

(27) A própria Constituição Federal reconhece isso ao vedar expressamente a a utilização, sem autorização legislativa específica, de recursos dos orçamentos fiscal e da seguridade social para suprir necessidade ou cobrir déficit de empresas, fundações e fundos, inclusive dos mencionados no art. 165, § 5ำ (artigo 167, VIII, da Constituição Federal). 
O êxito da implementação da política de medicamentos (assim como outras políticas públicas) depende essencialmente da maneira com que se relacionam dois fatores indissociáveis e permanentemente conflitantes entre si: as necessidades humanas consubstanciadas em direitos de um lado e as limitações materiais do Estado de outro. Em razão de imperativo constitucional e legal, o Poder Judiciário, quando instado a se manifestar sobre a implementação de direito social, não pode simplesmente ignorar as limitações impostas por força das normas constitucionais e leis orçamentárias; necessariamente haverá de levá-las em consideração, sob pena de pura e simplesmente substituir a vontade do legislador pela sua - e aqui está o compromisso do Poder Judiciário com a própria manutenção do Estado de Direito, no respeito ao exercício do Poder pelo Legislativo e pelo Executivo. Mas esse compromisso tem mão dupla: é que por ser guardião da Constituição e, conseqüentemente, do primado dos direitos fundamentais, o Poder Judiciário não poderá se omitir (como, de resto, também o Legislativo e o Executivo) diante do iminente perecimento de direitos sob a alegação da "reserva dos cofres cheios"; nessas hipóteses aos Poderes Executivo e Legislativo incumbirá o dever de: 1) a curto prazo, valerem-se da reserva de contingência orçamentária para lastrear as despesas decorrentes do cumprimento da ordem judicial e, se for o caso, determinar a abertura de crédito suplementar, especial ou extraordinário (art. 167, V, e $\S \S 2^{\circ}$ e $3^{\circ}$, da Constituição Federal, e art. 82 e ss. da Lei n. 4.320 de 17 de março de $1964^{(28)}$; e 2) a médio e longo prazos rediscutir e definir no fórum adequado - o Congresso Nacional - quais devem ser os objetivos e metas da administração pública para a realização de despesas de capital e as relativas aos programas de duração continuada (art. 165, $\S \S 10$ e $2^{\circ}$, da Constituição Federal), de maneira a adequá-los aos preceitos constitucionais fundamentais relativos aos direitos sociais, cuja violação tem sido recorrentemente reconhecida pelo Poder Judiciário.

\section{$V I-$ CONCLUSÕES}

Do que aqui foi exposto podemos pontuar algumas conclusões: 1) a efetivação dos direitos sociais, em razão da natureza destes, demanda ação pública efetivada de acordo com as políticas nacionais definidas pelos legisladores constituinte e ordinário; 2) existe uma política nacional de medicamentos norteada pelo controle de eficácia e atendimento a requisitos técnico-científicos; 3) existe um programa estatal que viabiliza a disponibilização de produto novo, ainda sem registro, para pacientes com doenças

(28) O artigo 82 e seguintes da Lei n. 4.320/64 dispõem sobre as autorizações de despesas não computadas ou insuficientemente dotadas na lei de orçamento - créditos adicionais. Classifica-os em suplementares, quando destinados a reforço de dotação orçamentária, especiais, quando destinados a despesas para as quais não haja dotação orçamentária específica e extraordinários, destinados a despesas urgentes e imprevisiveis, como as decorrentes de guerra, comoção interna ou calamidade pública. 
graves e que ameaçam a vida, na ausência de alternativas terapêuticas satisfatórias disponibilizadas no País - Programa de Acesso Expandido; 4) a política nacional de medicamentos é definida pelo Poder Legislativo e conduzida pelo Poder Executivo em fiel observância aos preceitos da Constituição e das leis; 5) ao Poder Judiciário incumbe, quando provocado por pessoa ou órgão legitimado, a salvaguarda do direito social à saúde desde que comprovada a insuficiência da ação estatal na preservação da vida por meio dos mecanismos próprios da política nacional referida, como eventualmente pode ocorrer na hipótese de não fornecimento de medicamento que, apesar de não constante de relação nacional, é necessário para garantir a saúde do bem-estar do paciente; (6) a implementação de políticas públicas deve compatibilizar a efetivação dos direitos sociais com as limitações materiais do Estado por meio do exercício harmonioso dos poderes de jurisdição, legislação e administração.

\section{REFERÊNCIAS BIBLIOGRÁFICAS}

BONAVIDES, Paulo. "Curso de direito constitucional". São Paulo: Malheiros Ed., 1999.

CAMPILONGO, Celso Fernandes. "Os desafios do Judiciário, um enquadramento teórico". In: FARIA, José Eduardo (Org.). "Direitos humanos, direitos sociais e justiça". São Paulo: Malheiros Ed., 1998.

CANOTILHO, J. J. Gomes. "Direito constitucional e teoria da constituiÇão", 4ª ed., Coimbra: Almedina, 2000.

ENZENSBERGER, Hans Magnus. "Visões da guerra civil". In: Guerra civil. São Paulo: Companhia das Letras, 1995.

FRISCHEISEN, Luiza Cristina Fonseca. "Políticas públicas". Aula proferida durante o I Curso de Especialização em Direito Público, 15 de agosto de 2001 - São Paulo. Escola Superior do Ministério Público do Estado de São Paulo, 2001.

HABERMAS, Jürgen. "O discurso filosófico da modernidade". São Paulo: Martins Fontes, 2002.

LOPES, José Reinaldo de Lima. "Crise da norma jurídica e a reforma do Judiciário". In: FARIA, José Eduardo (Org.). Direitos humanos, direitos sociais e justiça. São Paulo: Malheiros Ed., 1998.

SILVA, José Afonso da. "Curso de direito constitucional positivo". São Paulo: Malheiros Ed., 1999.

Superior Tribunal de Justiça. Disponível em: <http://www.stj.gov.br/webstj/>. Acesso em: 16 maio 2004.

WEIS, Carlos. "Direitos humanos contemporâneos". São Paulo: Malheiros Ed., 1999.

Who Health Organization. Disponivel em: <http://www.who.int/en/>. Acesso em: 16 maio 2004. 